\title{
Merco y RepTrak Pulse: \\ Comparación cualitativa de atributos, variables y públicos
}

\section{Merco \& RepTrak Pulse Qualitative comparison of attributes, variables and public}

\author{
María Pallarés Renau \\ Profesora asociada en el Dpto. de Ciencias de la Comunicación \\ (Universitat Jaume I) \\ Lorena López Font \\ Profesora contratada Doctora en el Dpto. de Ciencias de la Comunicación \\ (Universitat Jaume I)
}

Fecha de recepción: 19 de abril de 2017

Fecha de revisión: 19 de junio de 2017

Fecha de publicación: 1 de julio de 2017

Para citar este artículo: Pallarés Renau, M. y López Font, L. (2017): Merco y RepTrak Pulse: Comparación cualitativa de atributos, variables y públicos, Icono 14, volumen 15 (2), pp. 190-219. doi: 10.7195/ri14.v15i2.1077 


\section{MONOGRÁFICO}

\section{Resumen}

Este artículo localiza las nuevas acepciones de Reputación corporativa y sus implicaciones en la exponencial aparición de rankings y métricas de intangibles de las compañías. Tras una revisión teórica e histórica de los monitores, Merco y Rep Track Pulse, se realiza una comparación cualitativa de ambos; comparando dimensiones, atributos, metodologías, grupos de interés y resultados. El objetivo reside en encontrar las principales diferencias pedagógicas, heurísticas y sistemáticas (Nohlen, 2006). Cada monitor estudiado encuentra sus fortalezas en las debilidades del otro y viceversa. Se observará que Merco "no establece diagnóstico del nivel de compromiso de los grupos de interés, sino el grado en que la empresa cumple las condiciones para que se dé ese compromiso". (Carreras Et., al 2013, p.347) Y que RepTrak, "se trata de una escala racional que explica la emergencia de actitudes racionales, propias de poblaciones con cierto nivel de experiencia o información". (Carreras Et., al 2013, p.380).

Palabras clave: Reputación Corporativa - Merco - Rep Track Pulse - Grupos de interés Métrica y Gestión de Intangibles

\section{Abstract}

This article locates the new meanings of Corporate Reputation and their implications in the exponential appearance of rankings and metrics of intangible assets management of the companies. After a theoretical and historical review of the monitors studied, Merco and Rep Track Pulse, it was made a qualitative comparison of both; comparing dimensions, attributes, methodologies, interest groups and results. The objective is to find the main pedagogical, heuristic and systematic differences (Nohlen, 2006). Each monitor studied finds its strengths in the other's weaknesses and vice versa. It will be noted that Merco "does not make a diagnosis of the level of engagement of interest groups, but rather the degree to which the company fulfills the conditions for that commitment" (Carreras Et., al 2013, p.347). About RepTrak, "this is a rational scale that explains the emergence of rational attitudes, typical of populations with a certain level of experience or information". (Carreras Et., al 2013, p.380).

Key Words: Corporate Reputation - Merco - Reptrak Pulse - Interest Groups - Metrics and Intangible Asset Management 


\section{Introducción}

Lejos ya de concepciones exclusivamente mercantiles de las compañías como meras agentes de intercambio de productos o servicios a cambio de beneficio económico, y tras el asentamiento definitivo de la comunicación corporativa como gran aliado estratégico de las organizaciones, nos situamos sin punto de retorno en la era de la reputación. Encontramos en la actualidad textos de gran solvencia académica que re-colocan la definición de "reputación corporativa" de Charles Fombrun (1997) en su emblemática obra Reputation. Realizing Value from Corporate Image.

Autores como Isabel López Triana (2014) o Justo Villafañe (2012) han sabido enunciar en los últimos años axiomas claros y fundamentados que trasladan el concepto reputación desde su concepción vinculada a la opinión perceptiva de la ciudadanía, pasando por el reconocimiento de los comportamientos corporativos, hasta llegar al cumplimiento de expectativas o grados de escucha y colaboración entre la compañía y sus grupos de interés. La reputación corporativa es el gran colofón de la comunicación corporativa moderna.

La "nueva" reputación atrae inversión y retiene clientes y empleados (Carreras Et., al 2013: 23) por ello aparece un nuevo, potente y necesario reto para las direcciones de comunicación corporativa y/o las consultoras de comunicación; se trata de la unión del lenguaje económico, jurídico y comunicativo de las métricas en la gestión de intangibles. Medir la reputación para ser eficientes en su gestión se convierte en el nuevo escalón del corporate del siglo XXI; un cambio de siglo que supuso la explosión de monitores, índices y herramientas de medición de la reputación corporativa.

El presente trabajo parte de ese contexto para tomar como objeto de estudio principal dos monitores emblemáticos y fundamentales de carácter internacional vinculados a la reputación corporativa; Merco (Monitor empresarial de reputación corporativa, desde 2000) y RepTrak (Global RepTrak Pulse, desde 2005), con la intención de estudiar comparativamente las variables, los atributos y los grupos de interés contemplados en sus métricas. 


\section{MONOGRÁFICO}

\section{Material y método}

Este trabajo considerará la consecución de determinado grado de reputación corporativa como el gran objetivo final de la Comunicación Corporativa. Una marca reputada implica la identificación de sus grupos de interés con la misma cuando éstos reconocen en ella valores funcionales, sociales y emocionales con los que identificarse, obteniendo una experiencia positiva que sobrepasa incluso sus expectativas previas, y constituye la base para una relación duradera en el tiempo.

Para sustentar esta premisa se procederá primero a una clarificación del marco teórico sobre reputación corporativa y métrica, ya que sin variables de medida es complicado objetivar el grado de reputación conseguido. Después, procederemos a explicar la caracterización de ambos monitores para realizar una comparación cualitativa a partir del estudio de las variables de cada monitor, utilizando como fuente principal los informes ${ }^{1}$ publicados respecto al proceso de elaboración de los mismos.

Entendemos como comparación la interpretación valorativa de datos empíricos. Buscamos realizar una comparación pedagógica mediante la analogía, similitud 0 contraste; una comparación heurística resaltando lo peculiar de cada monitor y una comparación sistemática que enfatice las diferencias entre ambos (Nohlen, 2006).

Bajo éste estímulo y tratándose de modelos diferentes; métrica de reputación objetiva (Merco) y métrica de reputación subjetiva según grupos de interés (RepTrak), buscamos la comparación cualitativa. Por este motivo se presenta “la división pertinente porque afecta tanto al concepto de reputación que difiere en ambos casos, como a las metodologías de construcción y técnicas de medición establecidas para su cálculo" (Carreras Et., al 2013, p.345) y a los públicos considerados.

\begin{tabular}{|c|c|}
\hline Métrica de reputación objetiva & Métrica de evaluación subjetiva \\
\hline $\begin{array}{c}\text { Auditoría o valoración procedente de públicos } \\
\text { expertos. }\end{array}$ & $\begin{array}{c}\text { Punto de vista subjetivo de los grupos de } \\
\text { interés. }\end{array}$ \\
\hline
\end{tabular}


Merco y RepTrak Pulse: Comparación cualitativa de atributos, variables y públicos | 194 MONOGRÁFICO

\begin{tabular}{|c|c|}
\hline Métrica de reputación objetiva & Métrica de evaluación subjetiva \\
\hline Reputación como un objeto real. & Reputación como fenómeno psicosocial. \\
\hline $\begin{array}{c}\text { "Pretenden ser una fuente de información fiable } \\
\text { que indica a las empresas en qué grado han con- } \\
\text { seguido alcanzar los criterios necesarios de una } \\
\text { buena reputación" (Carreras Et., al 2013, p.346) }\end{array}$ & $\begin{array}{c}\text { "La conducta de valor del grupo de interés } \\
\text { no depende de la divulgación de auditorías } \\
\text { fiables de reputación sino de la forma en la } \\
\text { que el colectivo conoce esta información y la } \\
\text { interpreta" (Carreras Et., al 2013, p.347) }\end{array}$ \\
\hline Merco & RepTrak \\
\hline
\end{tabular}

Tabla 1: Tipología de métricas de reputación corporativa.

Fuente: Elaboración propia

Finalmente, observaremos como los datos extraídos mediante el análisis minucioso de los procesos públicos de elaboración de sendos monitores dan paso a un interesante debate académico y profesional sobre la monitorización de la reputación a través de la gran variedad de rankings y monitores, 0 a través de la creación de cuadros de mando propios de la reputación de cada compañía.

\section{Resultados}

Según el foro de reputación corporativa que integra las empresas más comprometidas en la gestión de este intangible (2011), la reputación es el conjunto de percepciones que tienen sobre la empresa los diversos grupos de interés, tanto internos como externos, consecuencia del comportamiento desarrollado por la misma a lo largo del tiempo y que describe su capacidad para distribuir valor a los mencionados grupos. Motivo por el que los profesionales de la comunicación, han asumido progresivamente funciones sobre la gestión de la misma y de los elementos que la componen.

“A partir de los años noventa el concepto de reputación va a ir adquiriendo carta de identidad propia hasta llegar a convertirse en uno de los constructos más prometedores para la gestión empresarial" (Carreras Et al., 2013, p.45). Así, la proliferación de monitores y propuestas metodológicas durante ésa década resulta incesante tanto en el ámbito profesional como en el académico. Sin embargo, el origen del interés por su monitorización se sitúa en la década de los cincuenta, haciendo referencia, por un lado “[...] al artículo de Pierre Martineau de $1958^{2}$ y por otro, a nivel práctico, de la mano de Fortune ${ }^{3}$, en "el ranking de medición de la reputación corporativa nombrado, Fortu- 
ne AMAC 7 (o Fortune 500), que empezó a gestarse en 1955, cuando la revista decidió publicar un ranking que incluía las 500 compañías más grandes de E.E.U.U, valoradas por sus ingresos brutos ajustados por impuestos". (Carrió, 2013, p. 78)

No es hasta la década de los ochenta, en 1984, cuando ésta misma publicación "saca a la luz los primeros rankings de las empresas más admiradas de Norteamérica y el concepto adquiere la relevancia que hoy se le reconoce." (Carreras Et al., 2013, p.44) En esta década se encuentra el origen de algunos modelos surgidos más adelante como Weigelt y Camerer (1988). Y en el ámbito académico, Peters y Waterman (1982).

Con los años noventa llega el éxito y la puesta en valor del concepto. En la segunda mitad, comienzan a desarrollarse los principales modelos de medición y a revisar los ya existentes. En 1997 la revista Fortune amplía su ranking Fortune AMAC con el Índice WMAC (World Most Admired Companies) Un año más tarde, el Reputation Institute abría paso al CRQ, índice actualmente conocido como Coeficiente de Reputación Corporativa ${ }^{4}$, y punto de partida del modelo RepTrak que aparecerá ocho años después (2006). En 1999, surge el Merco.

A principios del siglo XXI, Caruana y Chircop $(2000)^{5}$ [...] y contemporáneamente, Fombrun, Gardberg y Server (2000) emplearon la herramienta Reputation Quotent ${ }^{6}$, con el objetivo de medir la reputación en múltiples sectores, a través de dos fases: nominación y valoración. (Martínez León Et al., 2009, p.133)

A partir del 2000 aparecen nuevos estudios sobre reputación; el de Cravens, Goad y Ramamoorti (2003) o el de De Quevedo (2003) centrado en el análisis de la reputación de las entidades financieras españolas.

Ya entrado el siglo XXI la transparencia se vuelve imprescindible, la proyección de identidad se posiciona de forma más eficaz que la caracterización del producto y las precepciones corporativas se muestran tan importantes como las comerciales.

En 2006 aparece RepTrak "resultado de un estudio multinacional llevado a cabo por el Reputation Institute para entender cómo la reputación había evolucionado a lo largo de la década anterior" (Carrió, 2013, p.95) Rep Track añade nuevas di- 
Merco y RepTrak Pulse: Comparación cualitativa de atributos, variables y públicos | 196

mensiones y atributos a las que configuraban previamente el CRQ, "atributos que reflejan nuevos elementos afectivos [...], la comunicación corporativa y las iniciativas de la empresa, la cobertura en medios de comunicación y alineamiento de los empleados con la estrategia de la organización". (Carrió, 2013, p.95)

Creado por Charles Fombrun con el apoyo del Reputation Institute, Rep Track permite a las empresas conocer cuál es su reputación corporativa, aportando la posibilidad de elaborar estrategias empresariales que permitan modificar la imagen o reputación que tienen los grupos de interés de la empresa.

La década de los noventa bajo la visión imperante del Corporate determinó el salto hacia la gestión de intangibles.

El énfasis en la reputación corporativa, el intangible por excelencia, es un fenómeno de nuestro tiempo y lo seguirá siendo durante años porque la lógica multistakeholder se ha impuesto de manera definitiva y dicha lógica tiene como desiderátum la buena reputación y la revalorización de los recursos intangibles de las compañías (Villafañe, 2012, p.10)

Como señala Joan Costa en muchas de sus intervenciones "la gestión de la reputación, es a la revolución de los intangibles, lo que la publicidad fue a la revolución industrial".

Comprobamos a través de este recorrido histórico, cómo las principales herramientas de medición reputacional utilizan fundamentalmente dos tipos de procedimiento: Los rankings y las league tables. Los rankings, más vinculados al desarrollo de proyectos por parte de consultores, se presentan como clasificaciones de mayor a menor y las league tables que permiten evaluar a las empresas en función de dimensiones configuradas por atributos. Como establecen Carreras Et., al:

“Las metricas de reputación objetiva, como ocurre en el caso de Merco y Fortune AMAC o Fortune WMAC, entienden la reputación como un objeto real que tiene que ser representado de la forma más objetiva posible [...] Sin embargo las evaluaciones subjetivas del grupo de interés, al agregar la perspectiva multistakeholder, como ocurre con RepTrak, al medir aquello que los colectivos clave 


\section{MONOGRÁFICO}

opinan sobre una organización en particular, entiende la reputación como un fenómeno psicosocial, como las actitudes colectivas de los grupos de interés que se convierten en conductas". (2013, p.345)

En el ámbito académico, destaca el estudio de casos en el área de las ciencias sociales como herramienta de investigación fundamental de medición de la reputación corporativa, así como la inclusión de los cuadros de mando propios para la medición ad hoc de la reputación de las compañías.

\subsection{Orígenes y promotores}

Merco nace en 1999 con el "propósito de crear un ranking de reputación de empresas españolas que superara las debilidades metodológicas de los listados internacionales" (Carreras Et., al 2013, p.361). Se asienta en una metodología multistakeholder compuesta por cinco evaluaciones y doce fuentes de información. En el marco de la cátedra del Profesor Justo Villafañe en la Universidad Complutense de Madrid, es fruto de la colaboración con la consultora Villafañe \& Asociados, la empresa de estudios de mercado Análisis e Investigación y el grupo de comunicación Vocento.

Por otra parte RepTrak añade nuevas dimensiones y atributos y actualiza el $R e-$ putation Quotient (RQ), "se hizo público por primera vez en Madrid en noviembre de 2005 y en mayo de 2006 se presentó a la comunidad académica y empresarial en una sesión plenaria del $10^{\circ}$ Congreso Internacional Identity, Reputation and Competitiveness de Reputation Institute en Nueva York" (Carreras Et., al 2013, p.375). Es el resultado de un programa de investigación de 2004 propuesto por Corporate Excellence - Centre for Reputation Leadership (CE), el Foro de Reputación Corporativa (fRC) y el Instituto de Análisis de los Intangibles (IAI) y liderado por Charles Fombrun y su equipo de Reputation Institute.

Como despliegue de los principales agentes implicados que han dado como resultado las herramientas presentadas, se desarrolla la siguiente tabla compendio, reflejo de la colaboración entre entidades de diversa índole. 


\begin{tabular}{|c|c|c|c|c|c|c|c|}
\hline \multicolumn{4}{|c|}{ Orígenes } & \multirow{2}{*}{ Modelo } & \multicolumn{2}{|c|}{ Tipo de agente } & \multirow[b]{2}{*}{$\begin{array}{l}\text { Datos de interés } \\
\text { Doctor en Ciencias de la Información por } \\
\text { la UCM y Catedrático de Com. Audiovi- } \\
\text { sual y Publicidad y profesor de Imagen } \\
\text { Corp. en la misma Universidad. Es direc- } \\
\text { tor del informe anual sobre La comuni- } \\
\text { cación empresarial y la gestión de los } \\
\text { intangibles en España y Latinoamérica, } \\
\text { miembro del Instituto Español de Analis- } \\
\text { tas Financieros e Instituto de Análisis de } \\
\text { Intangibles Dircom, entre otras. }\end{array}$} \\
\hline \multirow{6}{*}{ 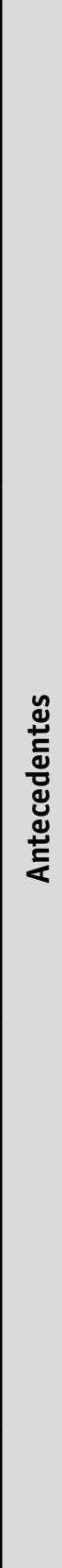 } & \multirow{4}{*}{ 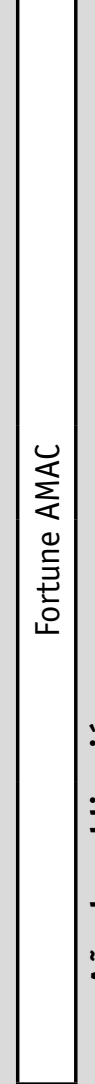 } & \multirow{4}{*}{\multicolumn{2}{|c|}{ 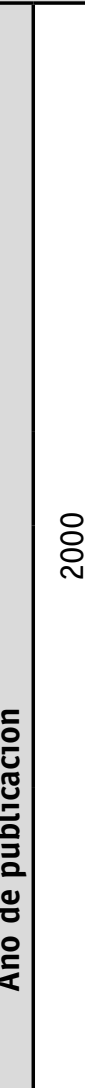 }} & & Académico & $\begin{array}{l}\text { Justo Villa- } \\
\text { fañe }\end{array}$ & \\
\hline & & & & \multirow{3}{*}{ 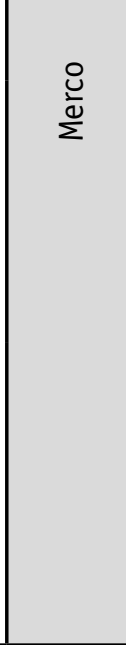 } & Consultoría & $\begin{array}{c}\text { Villafañe \& } \\
\text { Asociados }\end{array}$ & $\begin{array}{l}\text { Consultora especializada en gestión de } \\
\text { recursos intangibles empresariales. }\end{array}$ \\
\hline & & & & & $\begin{array}{l}\text { Grupo de Co- } \\
\text { municación }\end{array}$ & Vocento & $\begin{array}{l}\text { “[...] Grupo de comunicación multime- } \\
\text { dia; en España [...] cuenta con pre- } \\
\text { sencia destacada en todas las áreas de } \\
\text { información y entretenimiento [...] y } \\
\text { según EGM con una cobertura de más de } \\
\text { 30M de personas." (Vocento, 2015) }\end{array}$ \\
\hline & & & & & $\begin{array}{l}\text { Compañía de } \\
\text { invest. de } \\
\text { mercados }\end{array}$ & $\begin{array}{l}\text { Análisis e } \\
\text { Invest. }\end{array}$ & $\begin{array}{l}\text { "[...] Uno de los principales institutos } \\
\text { independientes de investigación de } \\
\text { mercados en España. En los últimos } \\
\text { años, [...] ha crecido notablemente, } \\
\text { pasando de } 78 \text { empleados y facturar } \\
\text { 2.6M en } 2004 \text { a } 360 \text { empleados y } 22.0 \mathrm{M} \\
\text { en } 2014^{\prime \prime 7} \text {. }\end{array}$ \\
\hline & \multirow[t]{2}{*}{2} & & $\stackrel{2}{\circ}$ & \multirow[t]{2}{*}{ 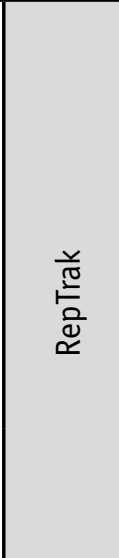 } & Académico & $\begin{array}{l}\text { Charles } \\
\text { Fombrun }\end{array}$ & $\begin{array}{c}\text { “Fundador y Presidente de Reputation } \\
\text { Institute. Fue miembro del claustro de la } \\
\text { Stern School of Business de la Universi- } \\
\text { dad de N.Y. entre } 1984 \text { y } 2004[\ldots] \text {. Asi- } \\
\text { mismo fue Profesor de la Wharton School } \\
\text { de la Universidad de Pensilvania entre } \\
1971 \text { y 1984, [...] y autor de Realizing } \\
\text { Value from the Corporate Image, editado } \\
\text { por Havard Business School Press en } \\
19966^{8} \text {. }\end{array}$ \\
\hline & & & & & Consultoría & $\begin{array}{l}\text { Reputation } \\
\text { Institute }\end{array}$ & $\begin{array}{l}\text { Consultora líder mundial especializada } \\
\text { en reputación, fundada en } 1997 \text { por los } \\
\text { doctores Fombrun y Cees van Riel. }\end{array}$ \\
\hline
\end{tabular}




\section{MONOGRÁFICO}

\begin{tabular}{|c|c|c|c|c|c|c|c|}
\hline \multicolumn{4}{|c|}{ Orígenes } & Modelo & \multicolumn{2}{|c|}{ Tipo de agente } & Datos de interés \\
\hline \multirow{3}{*}{ 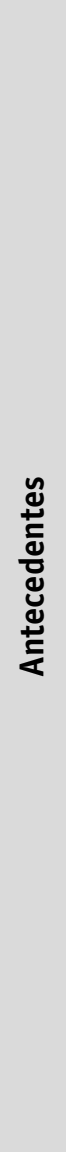 } & \multirow{3}{*}{ 잉 } & \multirow{3}{*}{\multicolumn{2}{|c|}{ 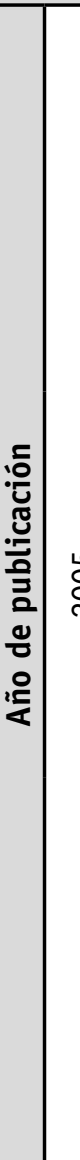 }} & \multirow{3}{*}{ 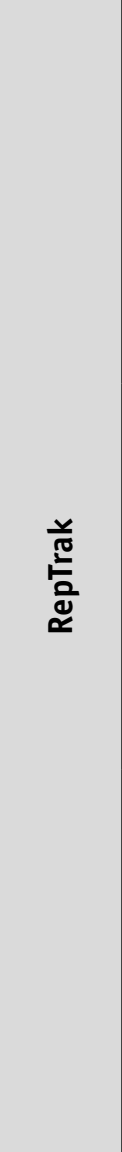 } & \multirow{3}{*}{$\begin{array}{l}\text { Iniciativas } \\
\text { empresariales }\end{array}$} & CE & $\begin{array}{l}\text { "Corporate Excellence - Centre for } \\
\text { Reputation Leadership es un laboratorio } \\
\text { de ideas sin ánimo de lucro creado para } \\
\text { impulsar la profesionalización y gestión } \\
\text { de los intangibles clave, como son la } \\
\text { reputación, la marca, la comunicación, } \\
\text { las métricas de intangibles y los asuntos } \\
\text { públicos. Nace de la fusión del fRC y e } \\
\text { IAI [...]". (CE, 2015) }\end{array}$ \\
\hline & & & & & & $\mathrm{fRC}$ & $\begin{array}{c}\text { "El Foro de Reputación Corporativa es } \\
\text { una asociación empresarial creada en } \\
2002 \text { para el intercambio de ideas y ex- } \\
\text { periencias relacionadas con la reputació } \\
\text { corporativa, [...] Entre las principales } \\
\text { actividades del fRC destacan la inves- } \\
\text { tigación y la difusión de modelos de } \\
\text { gestión de reputación corporativa [...]". } \\
\text { (fRC, 2015) }\end{array}$ \\
\hline & & & & & & IAI & $\begin{array}{l}\text { “Asociación sin ánimo de lucro, de } \\
\text { origen español, constituida en } 2004 \\
\text { por empresas, consultoras, escuelas de } \\
\text { negocio y organizaciones. Su objetivo e } \\
\text { dar forma y certeza a la investigación de } \\
\text { intangibles (marca, reputación corpo- } \\
\text { rativa, RSE, etc.), crear herramientas y } \\
\text { guías, y apoyar a las distintas iniciativa } \\
\text { en este campo". (Forética, 2015) }\end{array}$ \\
\hline
\end{tabular}

Tabla 2: Orígenes y promotores de Merco y RepTrak.

Fuente: Elaboración propia

\subsection{Procedimiento y metodología}

Merco parte de una visión amplia de la reputación, materializada en seis dimensiones, desglosadas en 18 atributos, directamente vinculados con el liderazgo reputacional. "Su metodología se alinea con las métricas fidedignas de reputación porque, como señala Justo Villafañe, la finalidad del proyecto fue crear una medida lo más fiable y objetiva posible sobre el reconocimiento del comportamiento corporativo excelente". (Carreras Et., al 2013, p.361) 
Merco y RepTrak Pulse: Comparación cualitativa de atributos, variables y públicos $\mid 200$ MONOGRÁFICO

La metodología de Merco se implementa en seis etapas asociadas a las evaluaciones de diferentes públicos:

La primera, de la que resultará el listado aproximado de cien empresas, se concentra en la elaboración de una gran encuesta de opinión (vía telemática o postal) al colectivo de directivos, incluidos ya en la base de datos de la empresa Análisis e investigación.

El universo de la encuesta a directivos está compuesto esencialmente por los designados por las empresas que cumplen al menos con una de las siguientes condiciones:

- Facturan más de 50 millones de euros en España.

- Han formado parte del ranking en años anteriores.

- Han formado parte de la población encuestada en años anteriores (MERCO, 2016, p.11)

En este cuestionario los directivos proponen el nombre de las 10 empresas que consideran más reputadas en España (exceptuando aquellas a las que pertenecen) y destacan la principal debilidad y los 3 factores por los que éstas disfrutan de dicha consideración. Después se solicita la inclusión de la empresa a la que pertenece el directivo en una posición dentro del ranking de esas diez.

Todos los cuestionarios recibidos son sometidos a un control de validez, destinado a detectar y evitar [...]:

- Recepción de cuestionarios manifiestamente irregulares [...]

- Multiplicación de cuestionarios [...]

- Voto corporativo [...]

- Cuestionarios fotocopiados [...] (MERC0, 2016, p.12). 
De este modo, el ranking provisional genera una lista de 96 empresas que tomarán parte en las siguientes fases de elaboración del ranking.

Obtenido el listado provisional, en la segunda etapa, estas empresas son valoradas por siete grupos de expertos con capacidad para:

Analizar y valorar el posicionamiento reputacional de las empresas evaluadas, dado su conocimiento experto acerca de uno o varios factores clave para la determinación de la reputación de una empresa. E Influir en la opinión pública desde su conocimiento experto, con el consiguiente impacto sobre la reputación de las organizaciones, más allá de su propio ámbito de actuación (MERC0, 2016, p.17)

En esta fase, se solicita a los expertos que evalúen de 0 a 100 puntos las empresas, atendiendo únicamente a las variables que constituyen su principal ámbito de especialización:

\begin{tabular}{|c|c|c|}
\hline GRUPO DE EXPERTOS & DIMENSIÓN MERCO & VARIABLE DE EVALUACIÓN \\
\hline \multirow{3}{*}{$\begin{array}{l}\text { ANALISTAS } \\
\text { FINANCIEROS }\end{array}$} & \multirow{3}{*}{$\begin{array}{l}\text { Resultados } \\
\text { Económico-Financieros }\end{array}$} & Resultados económico-financieros \\
\hline & & Solvencia \\
\hline & & $\begin{array}{l}\text { Calidad de la información } \\
\text { económica }\end{array}$ \\
\hline \multirow{2}{*}{ ONG } & \multirow{2}{*}{$\begin{array}{l}\text { Ética y Responsabilidad } \\
\text { Corporativa }\end{array}$} & Compromiso con la comunidad \\
\hline & & $\begin{array}{l}\text { Responsabilidad social y } \\
\text { medioambiental }\end{array}$ \\
\hline \multirow{2}{*}{$\begin{array}{l}\text { ASOCIACIONES DE } \\
\text { CONSUMIDORES }\end{array}$} & \multirow{2}{*}{$\begin{array}{l}\text { Calidad de la Oferta } \\
\text { Comercial }\end{array}$} & Calidad de producto-servicio \\
\hline & & $\begin{array}{l}\text { Respeto a los derechos del } \\
\text { consumidor }\end{array}$ \\
\hline SINDICATOS & Reputación Interna & Calidad laboral \\
\hline \multirow{3}{*}{$\begin{array}{l}\text { PERIODISTAS } \\
\text { ECONÓMICOS }\end{array}$} & \multirow{3}{*}{$\begin{array}{l}\text { Ética y Responsabilidad } \\
\text { Corporativa }\end{array}$} & Transparencia informativa \\
\hline & & Accesibilidad \\
\hline & & $\begin{array}{l}\text { Eficacia en la gestión de la } \\
\text { comunicación corporativa }\end{array}$ \\
\hline \multirow{3}{*}{$\begin{array}{c}\text { CATEDRÁTICOS DE } \\
\text { ECONOMÍA Y EMPRESA } \\
\text { Y PROFESORES DE } \\
\text { UNIVERSIDAD } \\
\text { ESPECIALIZADOS EN } \\
\text { EL AREA DE EMPRESA }\end{array}$} & \multirow{3}{*}{ Dirección y Gestión } & Calidad de la gestión empresarial \\
\hline & & Innovación \\
\hline & & Estrategia competitiva \\
\hline \multirow{3}{*}{$\begin{array}{l}\text { PERSONAS VINCULADAS } \\
\text { AL AREA DE } \\
\text { COMUNICACIÓN DIGITAL }\end{array}$} & \multirow{3}{*}{ Comunicación digital } & $\begin{array}{l}\text { Eficacia de su gestión en } \\
\text { comunicación digital }\end{array}$ \\
\hline & & Ética (honestidad y transparencia) \\
\hline & & $\begin{array}{l}\text { Innovación en comunicación } \\
\text { digital }\end{array}$ \\
\hline
\end{tabular}

Figura 1: Los cuestionarios de evaluación de expertos.

Fuente: Metodología e Informe de Verificación MERCO 2016, p.17-18 
En tercer lugar, se realiza la evaluación directa, desarrollada por el equipo técnico de Merco, que se encarga de contactar con cada una de las empresas para contrastar la información aportada. “Esta valoración requerirá a las empresas la acreditación de sus valores reputacionales, a través de la cumplimentación de un cuestionario y la presentación de la documentación que apoye los datos incluidos en dicho cuestionario". (MERC0, 2016, p.20)

La cuarta etapa centra la atención en el consumo y:

[...] tiene como objetivo la valoración de la reputación de las empresas seleccionadas por parte de la población general. Con este fin, Merco Empresas incluye entre sus fuentes de información una valoración específica acerca de la reputación corporativa de la empresa tomada de Merco Consumo, un monitor que incluye preguntas orientadas a conocer las diferentes facetas de la reputación corporativa y su evolución desde el punto de vista del consumidor final (MERC0, 2016, p.29)

La quinta y última fase incluye los resultados obtenidos en Merco Talento, un monitor independiente, que:

[...] trata de valorar el atractivo de las diferentes empresas como lugares para trabajar, partiendo en este caso de los puntos de vista de diferentes agentes: los trabajadores de las empresas, estudiantes universitarios, antiguos alumnos de escuelas de negocio, la población general y directores de recursos humanos. Asimismo, Merco Talento realiza una comparación de los principales indicadores de gestión de personas, a través de un proceso de benchmarking (MERC0, 2016, p.29)

Finalmente y tras cerrar las fases expuestas se extrae el ranking final "como la suma ponderada de las puntuaciones obtenidas en dichas etapas". (MERC0, 2016, p.30) 


\section{MONOGRÁFICO}

\begin{tabular}{|l|c|}
\hline Ponderación de RANKING DE DIRECTIVOS & $33 \%$ \\
\hline Ponderación de ANALISTAS FINANCIEROS & $6 \%$ \\
\hline Ponderación de SINDICATOS & $4 \%$ \\
\hline Ponderación de ASOCIACIONES DE CONSUMIDORES & $4 \%$ \\
\hline Ponderación de ONG'S & $4 \%$ \\
\hline Ponderación de PERIODISTAS DE INFORMACIÓN ECONÓMICA & $6 \%$ \\
\hline Ponderación de CATEDRÁTICOS Y PROFESORES DE ECONOMIA Y EMPRESA & $4 \%$ \\
\hline Ponderación de INFLUENTIALS & $4 \%$ \\
\hline Ponderación de MERCO CONSUMO & $10 \%$ \\
\hline Ponderación de MERCO PERSONAS & $10 \%$ \\
\hline Ponderación de EVALUACIÓN DIRECTA & $15 \%$ \\
\hline
\end{tabular}

Figura 2: Ponderaciones utilizadas en la elaboración del Ranking final de MERCO.

Fuente: Metodología e Informe de Verificación MERCO, 2016, p.25

Como puede observarse, los criterios de selección y el peso otorgado a cada público son determinantes para desarrollar las estrategias en las que se fundamenta:

Se triangulan los resultados porque se combinan los resultados obtenidos en encuestas de evaluación en diferentes grupos de interés con las auditorías de especialistas sobre méritos objetivos de empresas (Carreras Et., al 2013, p.362)

A diferencia de Merco, RepTrak estructura el fenómeno reputacional en siete dimensiones obtenidas tras realizar un análisis documental complementado con entrevistas en profundidad a directivos y focus group entre el público para determinar el primer listado que posteriormente se simplificará.

En la fase de generación de ítems, se realizaron entrevistas en profundidad a directivos, entrevistas semi-estructuradas a responsables de reputación, de comunicación corporativa, de recursos humanos, de marketing y de finanzas, que se completaron con los grupos de discusión a consumidores de diferentes sectores [...] Obtenida una lista exhaustiva de ítems relacionados con la reputación se procedió a su reducción mediante el análisis factorial exploratorio ${ }^{9}$ sobre los datos de una encuesta en línea en España. El resultado derivó en la formulación de la escala RepTrak con 21 atributos agrupados en 7 dimensiones. [...] 
Merco y RepTrak Pulse: Comparación cualitativa de atributos, variables y públicos | 204

Mediante un sistema de ecuaciones de regresión múltiple ${ }^{10}$, se establecieron las pendientes de cada indicador sobre su dimensión y los coeficientes que enlazan las dimensiones sobre la reputación global. [...] (Alloza y Martínez, 2007)

La estructura de pesos facilita el cálculo de todas las medidas, tanto de los componentes como de los índices ponderados por sus índices correspondientes, como del índice general que surge de la combinación lineal ponderada de las dimensiones. Esta doble estructura permite conocer el nivel general alcanzado y realizar diagnósticos sobre los puntos fuertes y débiles de la reputación. (Carreras Et., al 2013, p.376-377)

Los porcentajes asignados a cada peso se corresponden con cada una de las siete dimensiones que configuran RepTrak y que actualmente contempla 25 atributos:

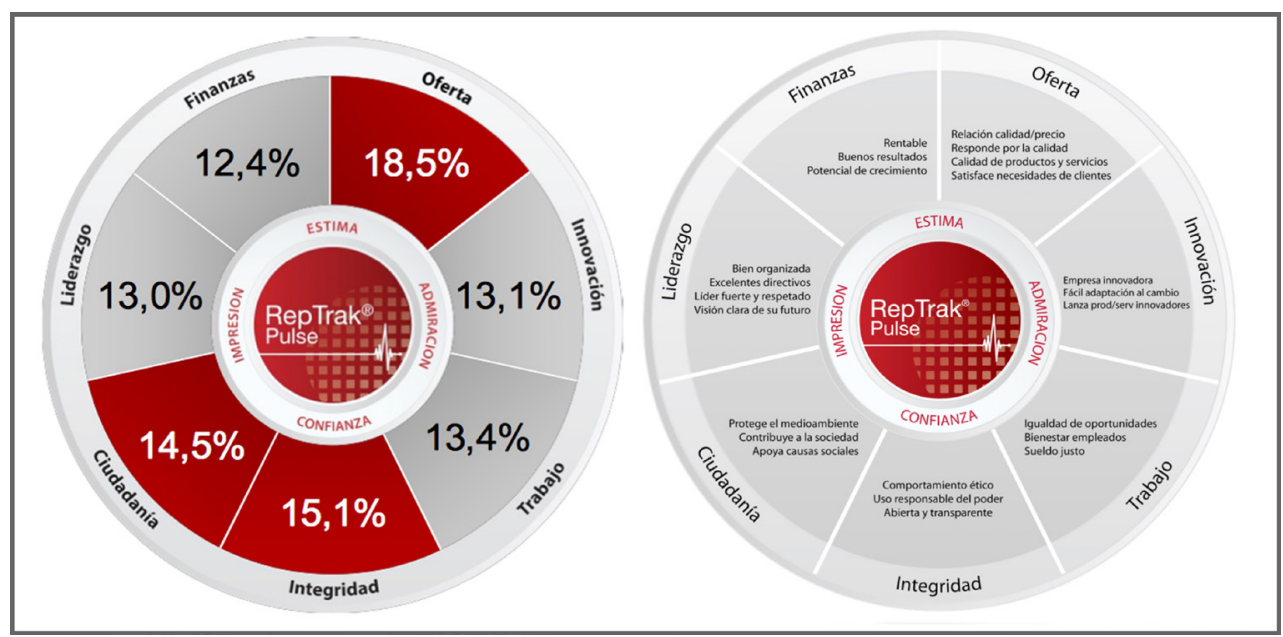

Figura 3: Agregación ponderada de pesos e indicador general de la reputación Fuente: Informe de resultados RepTrak España, 2016, p.6.

Se parte de una muestra representativa del público general de cada país ${ }^{11}$ donde se aplica. La configuración de la muestra alcanza más de 8.084 entrevistados, que entre febrero y marzo de 2016 han emitido un total de 32.883 valoraciones.

El público encuestado, ha de responder a tres o cuatro preguntas del indicador y debe estar familiarizado con una de las empresas por las que es preguntado. 


\section{MONOGRÁFICO}

A éste respecto el modelo RepTrak trata de evaluar por un lado

La reputación emocional, resultado de la valoración de los cuatro componentes que la forman: Buena Impresión, Estima, Confianza y Admiración. Y por otro lado la reputación racional como la agregación ponderada de las puntuaciones que obtiene una empresa en cada uno de los atributos multiplicado por el peso de éste ${ }^{12}$.

Definitivamente se ponderan las puntuaciones en base al peso específico de cada atributo en el marco de la dimensión correspondiente para obtener la puntuación del modelo. El cálculo se produce en una escala de 0 a 100 proporcionando una base estandarizada global respecto a la cual las compañías pueden compararse entre grupos de interés.

La recogida de información se produce de forma permanente y continua con el fin de obtener "series temporales, que permite además la aplicación de análisis matemático (ecuaciones estructurales y otras) capaces de modelar y de calcular los efectos causales de los indicadores de reputación en las actitudes y comportamientos de los grupos de interés". (Carreras Et., al 2013, p.375-376)

Ambos modelos se presentan como procesos, de forma sintetizada:

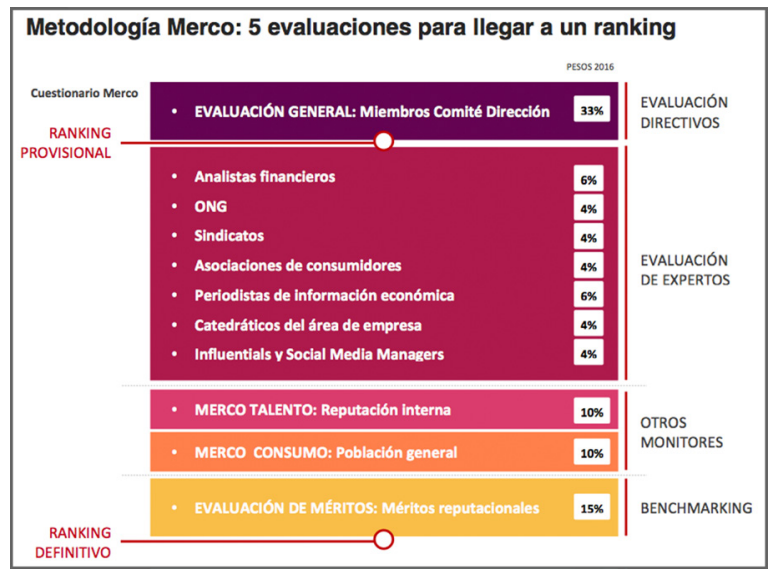

Figura 4: Esquema de funcionamiento de la metodología MERCO

Fuente: Metodología e Informe de Verificación MERCO, 2016:8 
Merco y RepTrak Pulse: Comparación cualitativa de atributos, variables y públicos | 206 MONOGRÁFICO

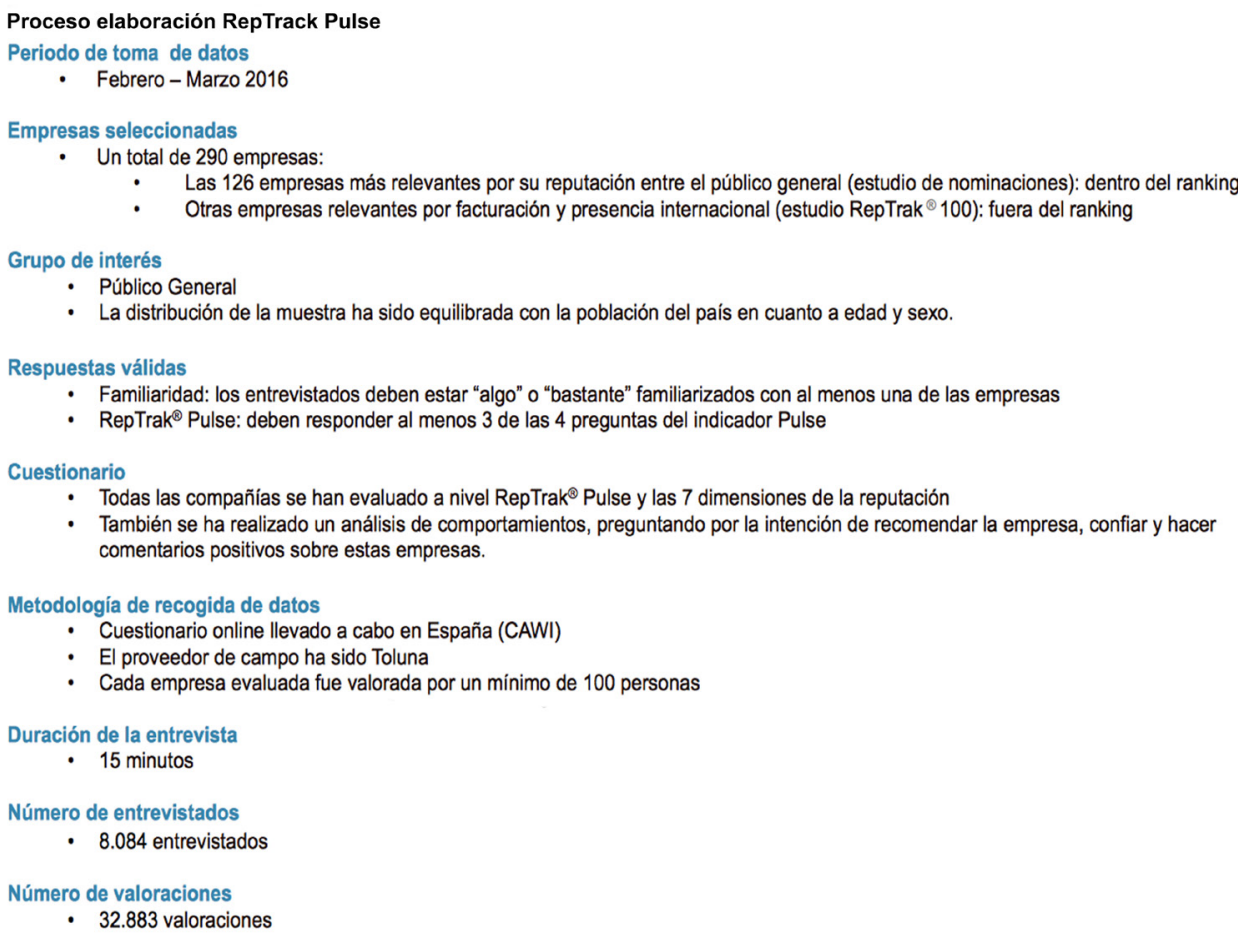

Figura 5: Proceso de elaboración de RepTrak

Fuente: Informe de resultados RepTrak España, 2016:13.

\subsection{Avances respecto a los modelos originarios}

Merco ha supuesto la integración de nuevos públicos no contemplados en muchos rankings hasta el momento. Y RepTrak la ampliación de elementos a considerar para explicar la conducta de los grupos de interés.

En el caso de Merco tras las encuestas realizadas a los principales directivos, a diferencia del Fortune AMAC, "la clasificación provisional no se publica, sino que es expuesta a dos evaluaciones más exigentes con personal altamente especializado: las auditorias de méritos y las evaluaciones de expertos". (Carreras Et., al 2013, p.364)

La inclusión de dichas auditorias y evaluaciones a la clasificación obtenida inicialmente, integra la metodología multistakeholder para obtener una representa- 


\section{MONOGRÁFICO}

ción lo más completa posible del reconocimiento social de la empresa, intentando superar la carencia de los rankings publicados en medios hasta el momento. Sin embargo, RepTrak toma en cuenta nuevos factores respecto a RQ, como “a) la legitimidad moral derivada de los valores universales (honestidad, equilibrio y benevolencia) y b) la capacidad de una organización". (Carreras Et., al 2013, p.380)

\subsection{Variables consideradas}

Ambos modelos se estructuran en torno a las percepciones que los individuos poseen respecto de una organización y aquellos valores que contribuyen a la generación de reputación; pero las dimensiones y atributos contemplados presentan diferencias sustanciales:

\begin{tabular}{|c|c|c|c|}
\hline \multicolumn{2}{|c|}{ Merco $^{13}$} & \multicolumn{2}{|c|}{ RepTrak $^{14}$} \\
\hline DIMENSIONES & ATRIBUTOS & DIMENSIONES & ATRIBUTOS \\
\hline $\begin{array}{l}\text { Resultados económico- } \\
\text { financieros }\end{array}$ & $\begin{array}{c}\text { Beneficio } \\
\text { Solvencia } \\
\text { Calidad de la informa- } \\
\text { ción económica }\end{array}$ & Finanzas & $\begin{array}{c}\text { Rentable } \\
\text { Buenos resultados } \\
\text { Potencial de creci- } \\
\text { miento }\end{array}$ \\
\hline $\begin{array}{l}\text { Calidad de la oferta } \\
\text { comercial }\end{array}$ & $\begin{array}{l}\text { Valores del producto } \\
\text { Valor de la marca } \\
\text { Servicio y atención al } \\
\text { cliente }\end{array}$ & Oferta & $\begin{array}{c}\text { Relación calidad- } \\
\text { precio } \\
\text { Responde por la } \\
\text { calidad } \\
\text { Calidad de productos y } \\
\text { servicios } \\
\text { Satisface necesidades } \\
\text { de clientes }\end{array}$ \\
\hline Talento & $\begin{array}{c}\text { Calidad laboral } \\
\text { Valores éticos y profe- } \\
\text { sionales } \\
\text { Identificación con el } \\
\text { proyecto empresarial }\end{array}$ & Integridad & $\begin{array}{l}\text { Comportamiento ético } \\
\text { Uso responsable del } \\
\text { poder } \\
\text { Abierta y trasparente }\end{array}$ \\
\hline
\end{tabular}


Merco y RepTrak Pulse: Comparación cualitativa de atributos, variables y públicos | 208

MONOGRÁFICO

\begin{tabular}{|c|c|c|c|}
\hline \multicolumn{2}{|c|}{ Merco $^{13}$} & \multicolumn{2}{|c|}{ RepTrak $^{14}$} \\
\hline $\begin{array}{l}\text { Ética y Responsabili- } \\
\text { dad Social Corporativa }\end{array}$ & $\begin{array}{l}\text { Comportamiento cor- } \\
\text { porativo ético } \\
\text { Contribución fiscal al } \\
\text { país } \\
\text { Responsabilidad social } \\
\text { y medioambiental }\end{array}$ & Trabajo & $\begin{array}{l}\text { Igualdad de oportuni- } \\
\text { dades } \\
\text { Bienestar empleados } \\
\text { Sueldo justo }\end{array}$ \\
\hline $\begin{array}{l}\text { Dimensión Internacio- } \\
\text { nal de la Empresa }\end{array}$ & $\begin{array}{c}\text { No de países en los que } \\
\text { opera } \\
\text { Cifra de negocio en el } \\
\text { extranjero } \\
\text { Alianzas estratégicas } \\
\text { internacionales }\end{array}$ & Ciudadanía & $\begin{array}{l}\text { Contribuye a la socie- } \\
\text { dad } \\
\text { Protección del medio } \\
\text { ambiente } \\
\text { Apoya causas sociales }\end{array}$ \\
\hline \multirow[t]{2}{*}{ Innovación } & $\begin{array}{l}\text { Inversiones en I+D } \\
\text { Nuevos productos y } \\
\text { servicios } \\
\text { Cultura de innovación } \\
\text { y cambio }\end{array}$ & Innovación & $\begin{array}{l}\text { Empresa innovadora } \\
\text { Adaptación fácil al } \\
\text { cambio } \\
\text { Lanza productos/servi- } \\
\text { cios innovadores }\end{array}$ \\
\hline & & Liderazgo & $\begin{array}{l}\text { Bien organizada } \\
\text { Excelentes directivos } \\
\text { Líder fuerte y respe- } \\
\text { tado } \\
\text { Visión clara de futuro }\end{array}$ \\
\hline
\end{tabular}

Tabla 3: Dimensiones y atributos de MERCO y Rep Track.

Fuente: Elaboración propia

\subsection{Públicos contemplados}

Tanto Merco como RepTrak inciden en la importancia de la metodología multistakeholder, pues la valoración que los públicos realizan de las dimensiones y atributos que configuran la reputación es inherente al concepto. Aún así, los stakeholders contemplados y el peso de sus valoraciones supone uno de los principales elementos de contraste de ambas herramientas. 


\section{MONOGRÁFICO}

\begin{tabular}{|c|c|}
\hline \multicolumn{2}{|c|}{ Determinación de públicos } \\
\hline Merco & RepTrak \\
\hline Comités de Dirección & \multirow{12}{*}{$\begin{array}{l}\text { Público } \\
\text { General }\end{array}$} \\
\hline Analistas financieros & \\
\hline ONG & \\
\hline Sindicatos & \\
\hline Asociaciones de consumidores & \\
\hline Periodistas de información económica & \\
\hline Catedráticos del área de empresa & \\
\hline Influentials y Social Media Managers & \\
\hline Expertos en RSC & \\
\hline Líderes de opinión & \\
\hline Merco Talento & \\
\hline Merco Consumo & \\
\hline Evaluación de Méritos & \multirow{2}{*}{$\begin{array}{l}\text { RepTrak habla de sociedad en general pues éste } \\
\text { término incluye diversos perfiles. }\end{array}$} \\
\hline $\begin{array}{l}\text { Merco presenta la división y especificación de } \\
\text { los públicos intervinientes en la valoración. }\end{array}$ & \\
\hline
\end{tabular}

Tabla 4: Determinación de públicos Merco y RepTrak.

Fuente: Elaboración propia

Mientras que RepTrak al contemplar la sociedad en general, parece otorgar un mayor peso al consumidor, Merco aunque tiene en cuenta 13 públicos distintos, concede mayor importancia a la valoración de directivos.

Merco cuenta con una muestra de 25.800 personas como indica el Informe sobre el Proceso de Elaboración de Merco 2016, que toma como referencia cifras relativas a la participación en 2015. Esta cifra se alcanza incluyendo los Directivos pertenecientes al Comité de Dirección de empresas que facturan más de 50 millones $€$ (1.260 directivos), y los públicos que intervienen en la generación de resultados una vez han sido elegidas las empresas y los líderes empresariales con mejor reputación en España. 


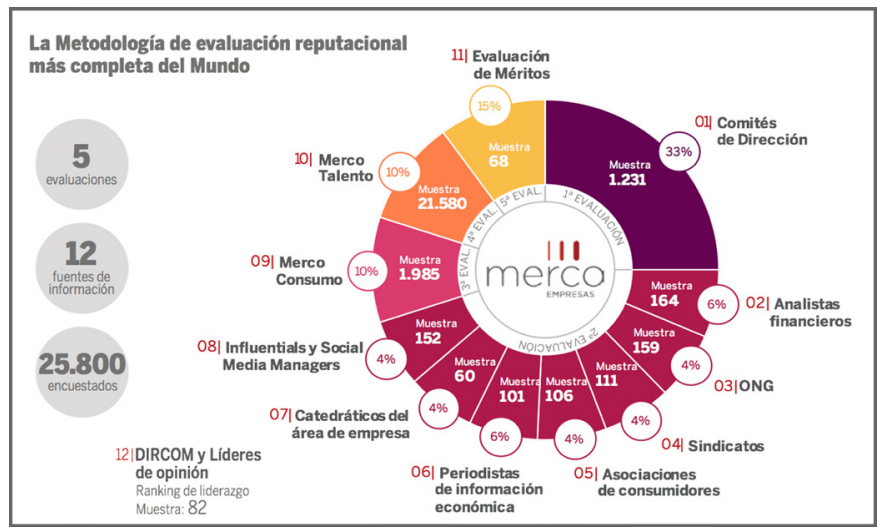

Figura 6: Públicos contemplados en MERCO

Fuente: Resultados MERCO Empresas, 2016:1

El desglose de públicos se presenta del siguiente modo:

“Analistas financieros: [...] puntúan de 0 a 100 los resultados económicofinancieros, la solvencia y la calidad de la información económica de las empresas. En 2015 participaron 160 analistas.

ONG: Responsables [...] puntúan de 0 a 100 el compromiso con la comunidad y la responsabilidad social y medioambiental de las empresas del ranking provisional (132 en 2015).

Sindicatos: Responsables [...] puntúan de 0 a 100 la calidad laboral de cada una de las empresas del ranking provisional (111 en 2015).

Asociaciones de consumidores: Responsables [...] puntúan de 0 a 100 la calidad del producto-servicio y el respeto a los derechos del consumidor de las diferentes empresas (111 en 2015).

Periodistas de información económica; [...] puntúan de 0 a 100 la transparencia informativa, la eficacia en la comunicación corporativa y la accesibilidad de las empresas del ranking provisional (100 en 2015). 


\section{MONOGRÁFICO}

Catedráticos de Universidad; [...] del área de empresa puntúan de 0 a 100 la calidad de la gestión empresarial, estrategia competitiva y la innovación (60 en 2015).

Expertos en RSC: Evalúan cinco variables: comportamiento ético; transparencia y buen gobierno; responsabilidad con los empleados; compromiso con el medio ambiente y el cambio climático; y contribución a la comunidad. Sólo incide en el ranking de responsabilidad y gobierno corporativo. (52 en 2015).

Líderes de opinión: Evalúan el liderazgo y la transferencia reputacional. Sólo incide en el ranking de líderes (78 en 2015).

Merco Talento. Empresas con más capacidad de atraer y retener talento: Una muestra de 17.555 trabajadores, 874 estudiantes universitarios, 798 antiguos alumnos de escuelas de negocio, 122 responsables de recursos humanos, 70 expertos headhunters y 2.092 ciudadanos identificaron las mejores empresas en España.

Merco Consumo. Población: (2.476 consumidores en 2015) valora la reputación comercial de las empresas en función de 10 variables: trayectoria, calidad-precio, calidad, innovación, ética, empatía, compromiso ecológico, compromiso social, atractivo para trabajar y buena para invertir.

Evaluación de Méritos. Técnicos de Análisis e Investigación; verifican directamente mediante un "cuestionario de méritos" la reputación atribuida a cada empresa, siguiendo criterios homologados con los principales índices (DJSI, GRI...)". (MERC0, 2015, p.38)

Por su parte, RepTrak alcanza las "70.300 entrevistas con consumidores en los 15 mercados más relevantes" (Prado, 2015, p.18). Durante el periodo de recogida que oscila entre febrero y marzo de 2016 en España, el número de entrevistados y de valoraciones han ascendido a 8.084 y 32.883 respectivamente. Y cada empresa evaluada fue valorada por un mínimo de 100 personas, como indica el informe de resultados RepTrak ${ }^{\circledR}$ España 2016. 
Como escala cognitiva multistakeholder, "el RepTrak [...] se ha utilizado en la población general, clientes, empleados y accionistas". (Carreras Et., al 2013, p.380). No obstante, atendiendo al "público general", la muestra se expone en términos menos específicos. Una muestra equilibrada con la población del país en cuanto a edad y sexo; destacando la superioridad en porcentaje del número de entrevistados con un nivel elevado de educación:

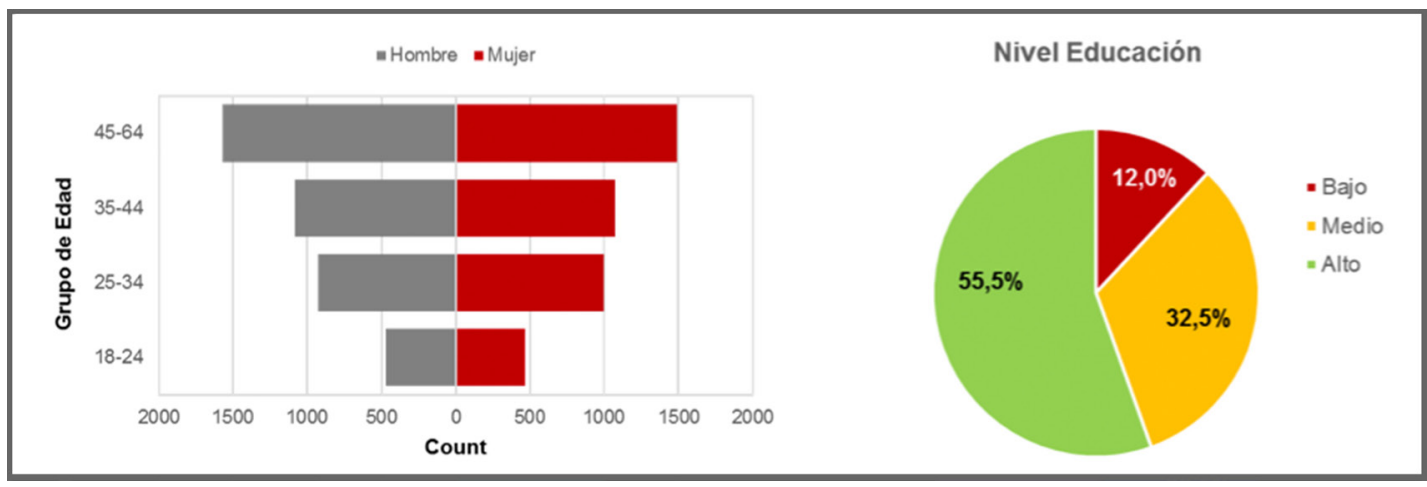

Figura 7: Muestra equilibrada del público de RepTrak

Fuente: Informe de resultados RepTrak España, 2016:13.

Por tanto, a diferencia del Merco qué, como

"auditoría formal de reputación suele adoptar la forma de una evaluación con criterios explícitos realizada por profesionales cualificados, que son quienes pueden determinar, de forma objetiva y fiable, el grado en que una corporación contiene y cumple con los ingredientes necesarios para tener una buena reputación". (Caverns Et al.,2003; Villafañe,2004 en Carreras Et., al 2013, p.345-346);

RepTrak, a efectos prácticos, mediante un sistema de encuestas y entrevistas, evalúa el grado en que una dimensión concreta afecta al vínculo emocional entre un grupo de interés concreto y la compañía, para determinar qué dimensiones tienen mayor impacto sobre el apoyo y la recomendación. 


\section{Discusión}

Colocar en paralelo los resultados de Merco y RepTrak en las últimas seis ediciones, permite corroborar de forma clara la incidencia en los resultados de las diferencias expuestas en el proceso de elaboración.

\begin{tabular}{|c|c|c|c|c|c|c|}
\hline \multicolumn{7}{|c|}{ Merco $^{15}$} \\
\hline & 2011 & 2012 & 2013 & 2014 & 2015 & 2016 \\
\hline 1 & SANTANDER & INDITEX & INDITEX & INDITEX & INDITEX & INDITEX \\
\hline 2 & INDITEX & MERCADONA & MERCADONA & MERCADONA & MERCADONA & MERCADONA \\
\hline 3 & TELEFÓNICA & REPSOL & SANTANDER & SANTANDER & SANTANDER & SANTANDER \\
\hline 4 & REPSOL & SANTANDER & REPSOL & REPSOL & REPSOL & BBVA \\
\hline 5 & LA CAIXA & TELEFÓNICA & IBERDROLA & TELEFÓNICA & TELEFÓNICA & REPSOL \\
\hline 6 & MERCADONA & IBERDROLA & TELEFÓNICA & BBVA & BBVA & TELEFÓNICA \\
\hline 7 & IBERDROLA & CAIXABANK & BBVA & IBERDROLA & IBERDROLA & CAIXABANK \\
\hline 8 & BBVA & $\begin{array}{l}\text { EL CORTE } \\
\text { INGLÉS }\end{array}$ & MAPFRE & MAPFRE & CAIXABANK & IBERDROLA \\
\hline 9 & $\begin{array}{l}\text { EL CORTE } \\
\text { INGLÉS }\end{array}$ & COCACOLA & COCACOLA & CAIXABANK & MAPFRE & MAPFRE \\
\hline & MAPFRE & CAIXABANK & CAIXABANK & G00GLE & G00GLE & G00GLE \\
\hline \multicolumn{7}{|c|}{ RepTrak $^{16}$} \\
\hline & 2011 & 2012 & 2013 & 2014 & 2015 & 2016 \\
\hline 1 & G00GLE & DAIMLER & DANONE & DANONE & SONY & BMW \\
\hline 2 & NOKIA & G00GLE & SONY & SONY & BMW & G00GLE \\
\hline 3 & DANONE & DANONE & G00GLE & G00GLE & G00GLE & $\mathrm{B} / \mathrm{S} / \mathrm{H}$ \\
\hline 4 & NESTLÉ & NESTLÉ & $\mathrm{B} / \mathrm{S} / \mathrm{H}$ & APPLE & DANONE & SAMSUNG \\
\hline 5 & MERCADONA & MERCADONA & NESTLÉ & MICHELIN & L’ORÉAL & MERCEDES \\
\hline 6 & DAIMLER & SONY & BMW & SAMSUNG & CAMPOFRIO & SONY \\
\hline 7 & SONY & DECATHLON & $\begin{array}{c}\text { VOLKSWA- } \\
\text { GUEN }\end{array}$ & BIMBO & NESTLÉ & NINTENDO \\
\hline 8 & COCA COLA & NOKIA & DAIMLER & BMW & SAMSUNG & ADIDAS \\
\hline 9 & ASTURIANA & MICHELIN & DECATHLON & ASTURIANA & ADIDAS & BIMBO \\
\hline 10 & $\mathrm{~B} / \mathrm{S} / \mathrm{H}$ & CAMPOFRIO & MICHELIN & TOYOTA & $\mathrm{B} / \mathrm{S} / \mathrm{H}$ & DANONE \\
\hline
\end{tabular}

Tabla 5: Top ten histórico Merco y Rep Track Pulse.

Fuente: Elaboración propia 
Merco y RepTrak Pulse: Comparación cualitativa de atributos, variables y públicos | 214 MONOGRÁFICO

Comprobamos mediante el contraste, cómo si ambos modelos conceptualmente analizan lo mismo, el Top ten no presenta coincidencias, hecho que da paso a un interesante debate, poniendo de relieve la casuística que aboca a la obtención de dispares resultados y poniendo de manifiesto aún más si cabe la peculiaridades de cada monitor.

Atendiendo a los stakeholders, en el caso de Merco, la crítica se centra en el elevado peso de los directivos y la ausencia de públicos como los agentes reguladores o los proveedores, que en algunos sectores son considerados de mayor importancia.

Además se cuestiona si es suficiente que los periodistas económicos sean los únicos representantes de los medios de comunicación, o que la ponderación aplicada a las valoraciones de clientes y trabajadores estén significadas principalmente por Asociaciones de Consumidores y sindicatos respectivamente.

Crítica contraria recibe el RepTrak por contemplar como público principal a la sociedad en general, por no atender al hecho de que, para muchas empresas y sectores, el consumidor no es el stakeholder más cualificado sobre el significado de la reputación en este contexto.

Vinculado al establecimiento de dimensiones y atributos, en el caso de Merco,

"Nos encontramos con un peso excesivo de los atributos vinculados a la "competencia" de las empresas a la hora de desarrollar sus actividades en detrimento de los atributos afectivos vinculados a la simpatía o identificación que genera la organización entre sus stakeholders. Consecuentemente el rendimiento de la empresa tiene un peso preponderante en el ranking". (Carrió 2013, p.90)

Y en el caso de RepTrak por centrarse en la sociedad en general,

“La definición de las dimensiones y atributos que configuran la reputación de una organización como su valoración tendrían que [...] tener en cuenta el impacto que las diferencias sectoriales, o tamaño de la organización pueden tener sobre la medición de la reputación". (Carrió 2013, p.98) 


\section{MONOGRÁFICO}

En esta misma línea, el hecho de que en ambos casos grandes empresas propongan la elaboración del listado de las organizaciones y públicos expertos a evaluar, invita a pensar que concurran intereses que perjudiquen parcial o totalmente la objetividad del proceso.

“La determinación de las dimensiones y atributos que configuran la reputación como en la fase inicial de valoración en que las encuestas a directivos, son las que acaban determinando el listado de empresas que a posteriori serán objeto del resto de evaluaciones [...]" (Carrió 2013, p.91), es objeto de crítica del Merco, pero:

“Para Justo Villafañe la fortaleza de estas métricas se encuentra precisamente en su fiabilidad, en su capacidad para determinar de forma imparcial el grado en que una organización posee determinada característica reputacional. Por esa razón se muestra partidario de que los evaluadores sean colectivos muy bien informados y que los procedimientos de evaluación sean rigurosos (Villafañe, 2004). En este sentido las medidas resultantes agregadas adquieren un mayor grado de credibilidad y solidez". (Carreras Et., al 2013, p.346)

La poca información que tiene disponible el público en general para opinar, dado que el resultado del que opina se basa en datos poco representativos, es otra de las críticas a RepTrak:

“Dado que los atributos individuales y las dimensiones significan cosas diferentes para los diferentes stakeholders y se perciben de forma diferente en términos de importancia ponderada, el modelo puede determinar qué atributos y dimensiones son claves en la construcción de la reputación del grupo en cuestión, siempre y cuando se aplique la encuesta a una muestra representativa de un grupo de stakeholders concreto". (Carrió 2013, p.98)

Nohlen (2002) propone pensar el método comparativo en sentido amplio, así desde la comparación sistemática nos hemos acercado a la historia y a la particularidad de cada monitor. Desde la comparación pedagógica, el contraste de las tablas de ambos monitores ha favorecido el orden y los hallazgos empíricos presentados. $\mathrm{Y}$ ha permitido conocer las causas del contraste existente en los resultados, con- 
Merco y RepTrak Pulse: Comparación cualitativa de atributos, variables y públicos | 216 MONOGRÁFICO

secuencia de la metodología particular aplicada por cada monitor (considerando públicos, variables y atributos).

La comparación heurística, acentúa el hecho de que ambos modelos encuentren sus principales fortalezas en las debilidades del otro y viceversa. Merco "porque no establecen diagnóstico del nivel de compromiso de los grupos de interés, sino el grado en que la empresa cumple las condiciones para que, teóricamente, se dé ese compromiso" (Carreras Et., al 2013, p.347). Y RepTrak como escala cognitiva, con validez de contenido y carácter predictivo, porque manifiesta consciencia de "que se trata de una escala racional y por tanto explica la emergencia de actitudes racionales, propias de poblaciones con cierto nivel de experiencia o información". (Carreras Et., al 2013, p.380)

\section{Notas}

[1] Signo de transparencia, ambos modelos presentan el proceso de elaboración previo a la obtención de resultados. MERCO por su parte lo hace en la web oficial http://www.merco.info/es en el apartado empresas. Y de la mano de Fernando Prado mediante el informe de resultados RepTrak ${ }^{\circledR}$ España 2016, lo hace en https://www.reputationinstitute.com

[2] Martineau, P. (1958). Sharper Focus for the Corporate Image. Harvard Bussines Review, 36, p.53.

[3] “Publicada por primera vez por el Grupo Editorial Time en el año 1930, sólo unos meses después de la caída de la bolsa del año 1929 [...] fue publicada mensualmente hasta el año 2000, cuando Time decidió publicarla bimensualmente. Éste ranking era el fruto de una reunión editorial en la que los trabajadores de la publicación fueron llamados para aportar ideas para el desarrollo futuro de la revista en clave interna. Un editor sugirió que sería útil crear una base de datos de las 500 empresas con más éxito financiero de Estados Unidos. Fortune tiene una circulación de 850.000 ejemplares y es considerada una de las revistas de negocios más importantes en Estados Unidos, junto con la revista Forbes". (Carrió, 2013, p.77)

[4] “Desde 1999, el Reputation Institute y Harris Interactive han estudiado la reputación de más de 200 empresas mediante encuestas a más de 100.000 personas y a más de 14 países utilizando el Coeficiente de Reputación Corporativa (CRQ)". (Carrió, 2013, p.91)

[5] “Su específico diseño dificulta su utilidad para empresas de otros sectores. (Martínez León Et al., 2009, p.133)

[6] Conocido como el medidor de Reputación Corporativa de Harris y Fombrun, publicado por el Wall Street Journal, fue creado específicamente para obtener las opiniones respecto de la empresa de consumidores, inversionistas, empleados y líderes de opinión. (Martínez León Et al., 2009, p.133)

[7] Análisis e Investigación. (1988-2017). La empresa. Recuperado de http://www.analisiseinvestigacion.com/acerca-de-aei/la-empresa.aspx

DOI: ri14.v15i2.1077 | ISSN: 1697-8293 | Julio - diciembre 2017 Volumen 15 № 2 | ICONO14 


\section{MONOGRÁFICO}

[8] Reputation Institute. (2015). Presentación del Estudio RepTrak Pulse España 2015. Recuperado de http://reputationinstitute.es/acerca-de-reputation-institute/category/liderazgo

[9] “El análisis factorial exploratorio, AFE, se usa para tratar de descubrir la estructura interna de un número relativamente grande de variables. La hipótesis a priori del investigador es que pueden existir una serie de factores asociados a grupos de variables. Las cargas de los distintos factores se utilizan para intuir la relación de éstos con las distintas variables". (Pérez y Medrano, 2010, p.58)

[10] “El análisis de regresión múltiple es una técnica de análisis multivariable en el que se establece una relación funcional entre una variable dependiente o a explicar y una serie de variables independientes o explicativas, en la que se estiman los coeficientes de regresión que determinan el efecto que las variaciones de las variables independientes tienen sobre el comportamiento de la variable dependiente. El modelo más utilizado es el modelo lineal, pues es el que requiere estimar un menor número de parámetros (Bernal, A. en Martínez, Martín, Martínez, Sanz de la Tajada y Vacchiano, 2000, pág. 584). [...] El modelo de regresión requiere que todas las variables, dependiente e independientes, estén medidas con escala métricas (Santesmases, 2001, pág. 237)". (Requena, 2005, p.126)

[11] Entre los países donde se realiza el estúdio se encuentran Alemania, Australia, Bélgica, Brasil, Canadá, China, Colombia, Corea del Sur, Dinamarca, España, Estados Unidos, Finlandia, Francia, Holanda, India, Irlanda, Italia, Japón, México, Noruega, Nueva Zelanda, Panamá, Perú, Portugal, Puerto Rico, Reino Unido, Rusia, Singapur, Sudáfrica, Suecia, Suiza, Taiwán y Turquía. (Reputation Institute,2013)

[12] Datos extraídos de RepTrak Pulse España. (2013). Marcas renombradas. Recuperado de http:// www.marcasrenombradas.com/wpcontent/uploads/2013/11/2013_RepTrak_Pulse_Espana.pdf

[13] Datos extraídos de: MERCO. (2015). El Proceso de Elaboración de Merco España 2015. Recuperado de http://www.merco.info/es/ranking-merco-empresas

[14] Datos extraídos de: Prado, F. (2016). RepTrak España 2016. Recuperado de https://www. reputationinstitute.com/CMSPages/GetAzureFile.aspx?path= \%5Cmedia\%5Cmedia\%5Cdocum ents\%5Creptrak-espana-spain-2016.pdf\&hash=46792bf96f005a532b4bcdbf77b3ba0cea6550c1 8db13119fde2b2745f50c3d0\&ext=.pdf

[15] Datos extraídos de: MERCO. (2016). Resultados. Recuperado de http://www.merco.info/es/

[16] Datos extraídos de: RepTrak Pulse España. (2016). Recuperado de https://www.reputationinstitute.com/Resources/Registered/PDF-Resources/2016-Spain-RepTrak.aspx

\section{Referencias}

Alloza, Á. (2002). La gestión estratégica del la marca. En Villafañe, J. (Ed.), El estado de la publicidad y el Corporate en España y Latinoamérica. Madrid, España: Pirámide.

Alloza, Á. (2012). Recuperar la confianza: La economía de la reputación en el nuevo paradigma de la empresa. Curso de verano 2012, Universidad Complutense San Lorenzo del Escorial. Madrid. Recuperado de http://pendientedemigracion. ucm.es/info/cv/descargas/cursos/73204.pdf 
Merco y RepTrak Pulse: Comparación cualitativa de atributos, variables y públicos $\mid 218$

Análisis e Investigación. (1988-2017). La empresa. Recuperado de http://www. analisiseinvestigacion.com/acerca-de-aei/la-empresa.aspx

Carreras, E., Alloza, Á. \& Carreras, A. (2013). Reputación Corporativa. Madrid: LID Editorial Empresarial. EAN-ISBN13:9788483567227.

Carrió, M. (2013). Creació d'una nova metodologia multistakeholder per a l'amidament de la reputació corporativa a partir de l'anàlisi de les 5 metodologies de referència: Fortune AMAC, Fortune WMAC, Merco, Coeficient de Reputació Corporativa (CRQ) i RepTrak (Tesis doctoral). Universitat Pompeu Fabra, Barcelona. Recuperado de http://hdl.handle.net/10803/120432

Corporate Excellence Centre for Reputation Leadership. (2015). Conócenos. Recuperado de http://www.corporateexcellence.org/index.php/Conocenos/ Quienes-somos.

Costa, J. (1995). Comunicación corporativa y revolución de los servicios. Madrid, España: Ciencias sociales.

Fombrun, C. (1996). Reputation. Realizing Value from the Corporate Image. Boston: Harvard Business School Press.

Hay Group. (2015). Press. Recuperado de http://www.haygroup.com/ww/press/ Details.aspx?ID=24631

IE \& fRC. (2011). Reputación corporativa. Introducción a la gestión

de los riesgos reputacionales. Recuperado de http://centrogobiernocorporativo. ie.edu/wp-content/uploads/sites/87/2013/11/Estudio-de-Reputación-yRiesgos-Reputacionales

López Triana, I. (2014). Observatorio global de Intangibles. En Villafañe, J. (Ed.). La comunicación empresarial y la gestión de los intangibles en España y Lationamérica. (pp.13-37) Madrid, España: GEDISA.

Martineau, P. (1958). Sharper Focus for the Corporate Image Harvard Bussines Review, 36, p.53.

Martínez León, I. y Olmedo Martínez, I. (2009). La medición de la reputación empresarial: Problemática y propuesta. Investigaciones Europeas de Dirección y Economía de la Empresa 15(2), 27-142. Universidad Politécnica de Cartagena. MERCO. (2015). El Proceso de Elaboración de Merco España 2015. Recuperado de http://www.merco.info/es/ranking-merco-empresas

MERC0. (2016). Metodología e Informe de Verificación. Recuperado de http://www. merco.info/es/ 


\section{MONOGRÁFICO}

MERCO. (2016). Resultados. Recuperado de http://www.merco.info/es/

Nohlen, D. (2006). Diccionario de ciencia política. México: Editorial Porrúa México y El Colegio de Veracruz.

Nohlen, D. \& Zovatto G., D. (2002). Instituciones Políticas en su contexto: Las vitrudes del método comparativo. Buenos Aires, Argentina: Rubinzal-Culzoni Editores.

Pérez, E. y Medrano, L. (2010). Análisis Factorial Exploratorio: Bases Conceptuales y Metodológicas. Revista Argentina de Ciencias del Comportamiento (RACC), 2(1), 58-66. Recuperado de http://www.redalyc.org/html/3334/333427068006/

Prado, F. (2016). RepTrak España 2016. Recuperado de https://www. reputationinstitute.com/CMSPages/GetAzureFile.aspx?path $=\sim \% 5 \mathrm{Cmedia} \% 5 \mathrm{Cm}$ edia\%5Cdocuments\%5Creptrak-espana-spain-2016.pdf\&hash $=46792 \mathrm{bf} 96 \mathrm{f005a}$ 532b4bcdbf77b3ba0cea6550c18db13119fde2b2745f50c3d0\&ext=.pdf

Reputation Institute. (2015). Presentación del Estudio RepTrak Pulse España 2015.

Recuperado de http://reputationinstitute.es/acerca-de-reputation-institute/ category/liderazgo

RepTrak Pulse España. (2016). Recuperado de https://www.reputationinstitute. com/Resources/Registered/PDF-Resources/2016-Spain-RepTrak.aspx

RepTrak Pulse España. (2013). Marcas renombradas. Recuperado de http://www. marcasrenombradas.com/wp-content/uploads/2013/11/2013_RepTrak_ Pulse_Espana.pdf

Requena Laviña, M. (2005). Capítulo IV: Metodología para el análisis de los datos de mercado". El desarrollo de las marcas gestionadas por la distribución. Análisis de las variables relevantes (Tesis doctoral). Universidad Pontificia Comillas, Facultad de Ciencias Económicas y Empresariales (ICADE), Madrid.

The Nielsen Company. (2015). About The Harris Poll. Recuperado de http://www. harrisinteractive.com/

Villafañe, J. (2004). La buena reputación. Madrid, España: Pirámide.

Villafañe, J. (2012). La comunicación intangible: reinventar la comunicación empresarial. Revista DIRCOM, 39. Recuperado de http://www.villafane.com/data/pdf/Lacomunicacion-intangible---reinventar-la-comunicacion-empresarial.pdf_226.pdf Villafañe, J. (2012). La buena empresa. Madrid, España: Pearson.

Villafañe, J. (Ed.). (2010). La comunicación empresarial y la gestión de los intangibles en España y Lationamérica. Madrid, España: Pearson.

Vocento. (2017). Somos. Recuperado de http://www.vocento.com/vocento_perfil.php 